\title{
New data on the Indus Kohistan seismic zone and its extension into the Hazara-Kashmir Syntaxis, NW Himalayas of Pakistan
}

\author{
MonaLisa - Azam A. Khwaja - M. Qasim Jan • \\ Robert S. Yeats • Ahmad Hussain • \\ Shahid A. Khan
}

Published online: 5 October 2008

(C) Springer Science + Business Media B.V. 2008

\section{Erratum to: J Seismol DOI 10.1007/s10950-008-9117-z}

Unfortunately, the parts "g" and "h" of Fig. 7 were missed by mistake.

The online version of the original article can be found under doi:10.1007/s10950-008-9117-z.

MonaLisa $(\varangle) \cdot$ M. Q. Jan

Department of Earth Sciences,

Quaid-i-Azam Univeristy, Islamabad, Pakistan

e-mail: lisa_qau@yahoo.com

\section{A. A. Khwaja}

Higher Education Commission Pakistan,

Islamabad, Pakistan

R. S. Yeats

Geosciences, Oregon State University and Earth Consultants International, Corvallis, OR, USA

\section{A. Hussain}

Geological Survey of Pakistan, Peshawar, Pakistan

\section{S. A. Khan}

Centre for Earthquake Studies, Islamabad, Pakistan
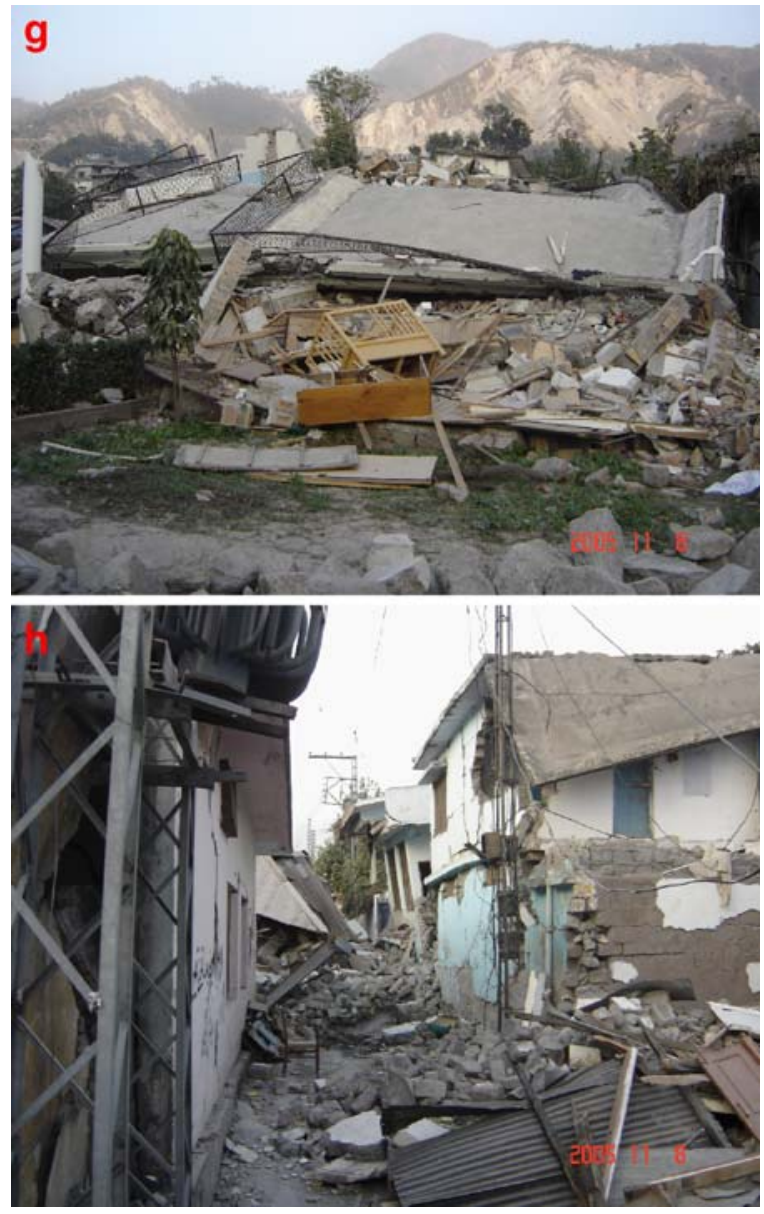

Fig. 7 Landslides (a-e; courtesy of National Engineering Services Pakistan) and destruction (f-h) in Muzaffarabad and Balakot 